引用格式:王梅,汪文雄. 农地整治权属调整中农户认知与行为的一致性研究 [J]. 资源科学, 2018, 40(1): 53-63. [Wang M,Wang W X. Consistency of farmers' cognition and behavior in the adjustment of land ownership under farmland consolidation[J]. Resources Science, 2018,40(1):53-63.] DOI : 10.18402/resci.2018.01.06

\title{
农地整治权属调整中农户认知与行为的 一致性研究
}

\author{
王 梅,汪文雄
}

(华中农业大学公共管理学院, 武汉 430070)

\begin{abstract}
摘 要: 农户关于农地权属调整的认知与行为的一致性关系不仅是农地权属调整理论研究的重要内容, 也是 其政策制定的重要参考。为了探索农地整治权属调整中农户认知与行为的内在联系, 本文在计划行为理论框架 下, 通过对湖北省 7 个市 (县) 644 个农户的问卷调查, 运用相关性分析法检验农户认知与行为的相关性, 并用多元有 序Logistic 模型分析受访者个体和家庭特征、耕地资源特征、村集体特征等因子对农户认知和行为影响的偏效应差 异。结果表明: 农户的认知状况在认知机制内部表现出不均衡性,农户行为的积极性缺乏; 在一致性检验中,相关 性分析和模型计量的结果均显示主观规范与行为的一致性较高, 行为态度和认知控制与行为之间基本上不具备一 致性。在此研究结果基础之上,提出关于信息公开、宣传动员、发挥组织作用等方面的政策建议, 以此促进农地权 属调整工作的顺利实施。
\end{abstract}

关键词:土地权属调整; 农户认知和行为; 计划行为理论; 相关性分析; Logistic 模型

DOI: 10.18402/resci.2018.01.06

\section{1 引言}

农地整治对协调人地矛盾、优化土地利用结 构、促进农业现代化、保障城镇空间发展具有重要 的意义,而土地权属调整作为农地整治的核心环 节,在降低土地破碎化、促进农业规模化、实现农村 可持续发展方面有着举足轻重的地位 ${ }^{[1]}$ 。农地整治 权属调整的实质是各土地权利人依据公认的权属 调整转换机制和相关标准, 在整治后合法地将其在 整治区内整治前所拥有土地权利换回的过程。土 地权属调整的类型分为国家与集体或者集体与集 体之间的土地所有权调整、农户之间土地承包经营 权和农地整治中新增耕地的土地使用权调整, 以及 土地他项权利的调整 ${ }^{[2]}$, 而本文讨论的权属调整主 要是指农户间的土地承包经营权的调整。农户作 为农地整治权属调整的主体, 其行为很大程度上决
定了农地整治权属调整的实施效果。虽然个体的 认知是行为的基础, 但是农户认知能否直观地作用 于农户行为, 并没有定论。有些研究认为农户认知 的改善会导致行为相应的变动 ${ }^{[3,4]}$, 但是也有研究提 出二者的不一致性 ${ }^{[5,6]}$ 。基于此,农户认知与行为的 一致性关系在农地整治权属调整领域成为一个值 得研究的课题并期望为促进农户有效参与农地整 治权属调整提供参考依据。

近年来,学者们围绕着农地整治的农户认知和 行为展开了广泛的研究: 在农户认知方面, 有学者 认为农户对农地整治认知水平的高低影响着农户 参与的意愿和积极性 ${ }^{[7,8]}$ 。在农户行为方面, 学者们 肯定了农户参与行为在农地整治中的积极作用 ${ }^{[9-11]}$, 但由于在农地整治中农户参与存在着积极性不高、 参与度较低、组织化程度低、缺乏法律及制度保障

收稿日期 : 2017-06-16; 修订日期: 2017-10-10

基金项目 : 国家自科基金项目(71373097; 71774065); 华中农业大学人文社会科学优秀青年人才支持项目(2015); 中央高校自主创新项目 (2662015PY204)。

作者简介 : 王梅,女,安徽六安人,硕士生,主要研究方向为农村土地整治与城乡统筹。E-mail: 1617233863@qq.com

通讯作者 : 汗文雄,E-mail: wwxylh2000@aliyun.com

http://www.resci.cn 
等问题 ${ }^{[12-14]}$, 所以学者们提出了加大宣传力度、突出 农户主体地位、成立农民组织、完善配套机制等对 策建议 ${ }^{[15-17]}$ 。尽管诸多的学者围绕着农地整治的农 户认知和参与行为分别进行了有益的探讨, 但在关 于农户认知和行为的一致性方面研究较少。

关于农地整治权属调整的研究多集中在现状 及存在问题 ${ }^{[18,19]}$ 、影响因素 ${ }^{[20]}$ 和方案设计上 ${ }^{[21,22]}$, 有关 农地整治权属调整中农户认知与行为的一致性研 究就更为鲜见。本文运用计划行为理论从相关性 和影响因素的角度来探讨农地整治权属调整中农 户的认知和行为的一致性。

\section{2 理论分析}

计划行为理论 (Theory of Planned Behavior, $\mathrm{TPB}$ ) 是社会心理学领域中解释和预测人类行为的 理论, 该理论为解释不同的人类行为提供了一个有 效的分析框架。 TPB 是在理性行为理论 (Theory of Reason Action, TRA)的基础上发展而来, 于 1991 年 因 Ajzen 发表《计划行为理论》一文而成熟, 他认为 行为的产生取决于执行某种行为的意向 ${ }^{[23]}$, 随着研 究领域的的扩大, 行为意向的概念被扩展为认知机 制, 而认知机制又由行为态度 (Attitude Toward The Behavior, ATT)、主观规范 (Subjective Norms, SN) 和 认知控制 (Perceived Behavior Control, PBC)共同构 成 ${ }^{[24]}$ 。 ATT指个体对执行某种行为的积极或消极的 态度; $\mathrm{SN}$ 是个体感知到的身边重要的人、组织或制 度对他执行或不执行某种行为所造成的压力; 个体 感知到的执行某种行为的控制能力称作为认知控 制 $(\mathrm{PBC})$ 。Ajzen还指出上述三个变量主要受到个 人以及社会文化等因素 (如智力、经验、年龄、文化 背景等)的影响, 计划行为理论的研究对象主要针对 一类群体的某种行为。学者们运用 TPB 探索了农 户行为受到认知机制中三个变量交互作用的影响 机理 ${ }^{[4,25]}$, 也有学者在 TPB 的基础上通过构建结构方 程模型研究了农户认知和行为的影响因素 ${ }^{[2,27]}$ 。

对农地整治权属调整而言, 农户对参与农地权 属调整的看法和态度首先决定了个体的行为意向， 所以将行为态度 (ATT)归结为农户对农地整治权属 调整作用的认知; 同时农户在权属调整中的行为受 到政策环境和邻里的影响, 这可表征为农户的主观 规范 (SN); 农户行为也受到客观的资源和成本的约
束, 即认知控制 (PBC)就代表农户对于自身禀赋和 开展权属调整难易程度的认知。所以在认知机制 构成和行为特征方面, 农地整治权属调整中农户认 知和行为符合这一特征, 本文将运用计划行为理论 对二者的一致性关系进行研究。

\section{3 数据来源与样本特征}

\section{1 问卷设计和数据来源}

问卷内容包括两大部分:第一部分为受访者及 家庭基本特征, 主要涉及受访者的年龄及受教育程 度、家庭收人等基本概况, 其中年龄层次的划分考 虑到农业劳动力老龄化的特点和年龄层内部分布 均匀性,共分为 4 个年龄段; 农业收人比重则参考农 户类型划分的依据并结合实际情况 ${ }^{[2,29]}$,划分为四 个区间段; 耕地面积是连续型的变量,参考不同类 型农户的种植规模划分为四个区间段; 耕地质量、 耕地破碎化程度、村经济水平和距城镇的远近则是 定性变量,依据农户感性认识的情况而确定。第二 部分主要反映农地整治权属调整的农户认知及行 为状况,其中认知机制包括行为态度 (ATT)、主观规 范 $(\mathrm{SN})$ 和认知控制 $(\mathrm{PBC})$ 。

湖北省国土厅组织专家遵循相关原则将湖北 省细分为低山工程模式 $\left(I_{1}\right) 、$ 丘陵工程模式 $\left(I_{2}\right)$ 、平岗 工程模式 $\left(\mathrm{II}_{1}\right) 、$ 岗前平原工程模式 $\left(\mathrm{II}_{2}\right)$ 等 7 个农地整 治工程模式区。本文数据来源于 2016 年 8 月至 9 月 对湖北省农地整治项目区的调查,调研区主要涉及 了岗前平原工程模式区 (嘉鱼县、鄂州市鄂城区和 华容区、天门市、沙洋县)和丘陵工程模式区(咸宁市 咸安区、大冶市、安陆市、)共 7 个市(县)。平原和丘 陵模式区虽然地形和农地面积差异较大,但是整治 的重点都放在灌排设施和防护林网的建设,农作物 主要以一季水稻加一季旱粮为主, 经济社会状况较 类似。根据普遍性和全面性的原则, 采用随机抽样 和分层抽样相结合的方法在每个市(县)选取 2 3个 乡镇,每个乡镇随机选取 3 4 个行政村进行访谈式 问卷调查。此次调查共访问 649 个农户,剔除有错 误或有遗漏信息的问卷后, 获取 644 份有效问卷, 问 卷有效率 $99.23 \%$ 。

\section{2 样本特征}

通过对 644 份问卷的统计性分析可得出样本的 基本特征, 具体情况如表 1 所示。从受访者及家庭 
表 1 样本基本特征

Table 1 Basic feature of sample farmers

\begin{tabular}{|c|c|c|c|c|c|c|c|c|c|c|c|}
\hline & \multicolumn{3}{|c|}{ 受访者及家庭特征 } & \multicolumn{4}{|c|}{ 耕地资源特征 } & \multicolumn{4}{|c|}{ 村集体特征 } \\
\hline 项目 & 分组 & 样本数 & 比例/\% & 项目 & 分组 & 样本数 & 比例/\% & 项目 & 分组 & 样本总数 & 比例 $/ \%$ \\
\hline \multirow[t]{2}{*}{ 性别 } & 男 & 341 & 52.95 & \multirow{4}{*}{$\begin{array}{l}\text { 耕地 } \\
\text { 面积 } \\
/ \mathrm{hm}^{2}\end{array}$} & $\leqslant 0.33$ & 323 & 50.16 & \multirow{5}{*}{$\begin{array}{l}\text { 村经济 } \\
\text { 发展水平 }\end{array}$} & 很低 & 25 & 3.88 \\
\hline & 女 & 303 & 47.05 & & $0.33 \sim 0.67$ & 179 & 27.80 & & 较低 & 127 & 19.72 \\
\hline \multirow[t]{4}{*}{ 年龄/岁 } & $\leqslant 40$ & 40 & 6.21 & & $0.67 \sim 1.33$ & 93 & 14.44 & & 一般 & 348 & 54.04 \\
\hline & $40 \sim 55$ & 219 & 34.01 & & $>1.33$ & 49 & 7.61 & & 较高 & 130 & 20.19 \\
\hline & $55 \sim 65$ & 228 & 35.40 & \multirow{5}{*}{$\begin{array}{l}\text { 耕地破碎 } \\
\text { 化程度 }\end{array}$} & 很低 & 127 & 19.72 & & 很高 & 14 & 2.17 \\
\hline & $>65$ & 157 & 24.38 & & 较低 & 118 & 18.32 & \multirow{5}{*}{$\begin{array}{l}\text { 距城镇 } \\
\text { 距离 }\end{array}$} & 很远 & 27 & 4.19 \\
\hline \multirow{4}{*}{$\begin{array}{l}\text { 户主受教 } \\
\text { 育程度 }\end{array}$} & 小学及以下 & 349 & 54.19 & & 一般 & 109 & 16.93 & & 较远 & 150 & 23.29 \\
\hline & 初中 & 245 & 38.04 & & 较高 & 233 & 36.18 & & 一般 & 106 & 16.46 \\
\hline & 高中 & 46 & 7.14 & & 很高 & 57 & 8.85 & & 较近 & 244 & 37.89 \\
\hline & 大专及以上 & 4 & 0.62 & 耕地 & 很低 & 13 & 2.02 & & 很近 & 117 & 18.17 \\
\hline \multirow{4}{*}{$\begin{array}{l}\text { 农业收人 } \\
\text { 比重/\% }\end{array}$} & $\leqslant 10$ & 352 & 54.66 & 质量 & 较低 & 83 & 12.89 & \multirow{2}{*}{$\begin{array}{l}\text { 成立农村社 } \\
\text { 会经济组织 }\end{array}$} & 是 & 116 & 18.01 \\
\hline & $10 \sim 50$ & 204 & 31.68 & & 一般 & 254 & 39.44 & & 否 & 528 & 81.99 \\
\hline & $50 \sim 90$ & 9 & 1.40 & & 较高 & 245 & 38.04 & - & - & - & - \\
\hline & $>90$ & 79 & 12.27 & & 很高 & 49 & 7.61 & - & - & - & - \\
\hline
\end{tabular}

特征看, 受访农民的男女比例较适中, 男性略大于 女性; 受访农民的年龄主要集中在 40 岁到 65 岁之 间 (其比例达 69.41\%); 受教育程度是小学及以下的 农户占 $54.19 \%$, 而高中及以上的不足 $8 \%$; 农业收人 比重大于 $50 \%$ 的样本占比为 $13.67 \%$ 。从耕地资源 特征看,耕地面积不超过 $0.33 \mathrm{hm}^{2}$ 的农户达 $50.16 \%$, $0.67 \mathrm{hm}^{2}$ 以上的仅 $22.05 \%$; 耕地细碎化程度“较高” 和“很高”的样本达 $45.03 \%$, “很低” 和“较低”的比例 达 $38.04 \%$; $45.65 \%$ 的农户反映耕地质量具有 “较高” 或 “很高” 的水平, 认为 “很低” 和 “较低” 的仅占 $14.91 \%$, 说明调查区初步具备土地权属调整的诉求 和基本条件。从村集体特征看,超过一半的农户反 映本村经济水平 “一般”; 绝大数村庄距城镇的距离 较近，仅有不到 5\%的农户所在的村庄距城镇很远； 而受访者所在村集体成立农村经济组织的样本较 小,仅占 $18.01 \%$ 。

\section{4 数据处理与分析}

\section{1 数据处理}

此次问卷调查的数据涉及分类变量和连续变 量, 分类变量采用 Likert五级量表形式,根据农户对 问题的回答, 即“很差(完全不赞同、未参与)”、“较差 (不赞同、消极参与)”、“一般 (基本赞同、被动参 与)”、“较好(比较赞同、较积极参与)”、“很好 (完全
赞同、非常积极参与)”的递增程度, 分别赋值 $1 、 2 、$ $3 、 4 、 5$, 通过处理得到农户认知 (Recognize, 由 ATT、 $\mathrm{SN}$ 和 $\mathrm{PBC}$ 构成) 分值和行为 (Behavior) 分值, 分值越 高表明农户对权属调整的认知情况越好、行为越积 极。

\subsection{1 农地整治权属调整农户认知的量化处理}

农户对农地整治权属调整认知状况主要通过 表 2 中农户认知机制的观测指标来反映,其中行为 态度包含 12 个观测指标, 记为 $A t t_{i}$; 主观规范包含 13 个观测指标, 记为 $S n_{i}$; 认知控制包含 6 个观测指标, 记为 $P b c_{i}$, 具体含义见表 2 。

要计算农户最终的认知分值必须首先确定各 观测指标的权重, 而因子分析法在确定权重方面具 有客观性强的特点, 因此本文运用 SPSS 21.0 软件 的降维功能来确定观测指标权重。在确定权重之 前, 需要进行信度和效度检验以判断是否适合用因 子分析法,表 3 的结果显示 ATT、SN 和 PBC 的 $\mathrm{KMO}$ 值和 P 值均满足 KMO 检验和 Bartle 检验的标准。 根据各个指标的提取值, 再进行归一化处理, 得到 农户的行为态度 $(\mathrm{ATT})$ 、主观规范 $(\mathrm{SN})$ 、认知控制 (PBC)各自观测指标的权重,最终结果如表4所示。

权重确定之后农户的认知总分值可以通过加 权平均的方法求得, 从图 1(见57页)中可以看出行 
为态度的分值高于其他两个维度,集中分布在 3 4 4 5 两个分数段,表明农户对土地权属调整的积极 作用有着较清楚的认知。而主观规范和认知控制 在 2 3 和 3 4 两个分数段分布较均衡, 在 $2 \sim 3$ 分值段 中占比均在 50\%左右,3 4 分值段中占比接近 $40 \%$ 。

\subsection{2 农地整治权属调整中农户行为的量化处理}

农户行为主要通过农地整治权属调整中农户 参与的情况反映, 依据表 5 的行为分类情况, 依次赋
予 1 5 的分值。从总体上看, 样本中已经参与权属 调整的农户与未参与的农户数量之比约为 $1: 2$, 说 明在调查区域的农地整治权属调整活动中,农户的

表 3 样本数据信度和效度检验结果

Table 3 Results of reliability and validity test of sample statistic

\begin{tabular}{cccc}
\hline & ATT & SN & PBC \\
\hline KMO & 0.82 & 0.83 & 0.88 \\
Sig. & 0.00 & 0.00 & 0.00 \\
\hline
\end{tabular}

表 2 样本农户认知机制观测指标

Table 2 Observed indexes of sample farmers' cognition

\begin{tabular}{|c|c|c|c|c|c|}
\hline \multicolumn{2}{|c|}{ 行为态度 $($ ATT $)$} & \multicolumn{2}{|r|}{ 主观规范( SN) } & \multicolumn{2}{|r|}{ 认知控制 (PBC) } \\
\hline 代码 & 指标 & 代码 & 指标 & 代码 & 指标 \\
\hline$A t t_{1}$ & 提高耕地利用率 & $S n_{1}$ & 邻居对自己开展权属调整的态度 & $P b c_{1}$ & 对权属调整困难度认知 \\
\hline$A t t_{2}$ & 降低劳动成本 & $\mathrm{Sn}_{2}$ & 村精英对自己开展权属调整的态度 & $\mathrm{Pbc}_{2}$ & 对权属调整成功结果的预判 \\
\hline $\mathrm{Att}_{3}$ & 降低灌溉成本 & $\mathrm{Sn}_{3}$ & 村委会对自己开展权属调整的态度 & $\mathrm{Pbc}_{3}$ & 对相关信息的掌握程度 \\
\hline $\mathrm{Att}_{4}$ & 提高农机生产率 & $\mathrm{Sn}_{4}$ & 乡政府对自己开展权属调整的态度 & $\mathrm{Pbc}_{4}$ & 对相关技能的掌握程度 \\
\hline $\mathrm{Att}_{5}$ & 提高作物产量 & $S n_{5}$ & 权属调整行为受邻居的影响程度 & $\mathrm{Pbc}_{5}$ & 对自身拥有参与权属调整时间的评价 \\
\hline$A t t_{6}$ & 促进现代农业发展 & $S n_{6}$ & 权属调整行为受村精英的影响程度 & $\mathrm{Pbc}_{6}$ & 对自身参与权属调整支付能力的评价 \\
\hline $\mathrm{Att}_{7}$ & 丰富景观类型 & $S n_{7}$ & 权属调整行为受村委会的影响程度 & - & - \\
\hline$A t t_{8}$ & 优化景观格局 & $S n_{8}$ & 权属调整行为受乡政府的影响程度 & - & - \\
\hline$A t t_{9}$ & 改善生态环境 & $S n_{9}$ & 邻居积极开展权属调整的程度 & - & - \\
\hline$A t t_{10}$ & 减少地界冲突 & $S n_{10}$ & 村精英积极开展权属调整的程度 & - & - \\
\hline$A t t_{11}$ & 减少农业生产冲突 & $S n_{11}$ & 村委会积极开展权属调整的程度 & - & - \\
\hline $\operatorname{Att}_{12}$ & 提高农村和谐程度 & $S n_{12}$ & 乡政府积极开展权属调整的程度 & - & - \\
\hline- & - & $S n_{13}$ & 村合作组织积极开展权属调整的程度 & - & - \\
\hline
\end{tabular}

表4 因子分析法所得的指标权重

Table 4 Quota weight from factor analysis

\begin{tabular}{|c|c|c|c|c|c|c|c|c|c|c|c|}
\hline \multicolumn{4}{|c|}{ 行为态度 (ATT) } & \multicolumn{4}{|c|}{ 主观规范(SN) } & \multicolumn{4}{|c|}{ 认知控制 (PBC) } \\
\hline 指标 & 初始 & 提取 & 权重 & 指标 & 初始 & 提取 & 权重 & 指标 & 初始 & 提取 & 权重 \\
\hline$A t t_{1}$ & 1 & 0.536 & 0.06 & $S n_{1}$ & 1 & 0.572 & 0.06 & $P b c_{1}$ & 1 & 0.795 & 0.16 \\
\hline $\mathrm{Att}_{2}$ & 1 & 0.697 & 0.08 & $\mathrm{Sn}_{2}$ & 1 & 0.698 & 0.07 & $\mathrm{Pbc}_{2}$ & 1 & 0.757 & 0.15 \\
\hline $\mathrm{Att}_{3}$ & 1 & 0.676 & 0.08 & $\mathrm{Sn}_{3}$ & 1 & 0.633 & 0.06 & $\mathrm{Pbc}_{3}$ & 1 & 0.900 & 0.18 \\
\hline $\mathrm{Att}_{4}$ & 1 & 0.649 & 0.08 & $\mathrm{Sn}_{4}$ & 1 & 0.713 & 0.07 & $\mathrm{Pbc}_{4}$ & 1 & 0.899 & 0.18 \\
\hline $\mathrm{Att}_{5}$ & 1 & 0.555 & 0.06 & $\mathrm{Sn}_{5}$ & 1 & 0.774 & 0.08 & $\mathrm{Pbc}_{5}$ & 1 & 0.818 & 0.17 \\
\hline$A t t_{6}$ & 1 & 0.656 & 0.08 & $S n_{6}$ & 1 & 0.800 & 0.08 & $\mathrm{Pbc}_{6}$ & 1 & 0.812 & 0.16 \\
\hline$A t t_{7}$ & 1 & 0.815 & 0.09 & $S n_{7}$ & 1 & 0.751 & 0.08 & - & - & - & - \\
\hline$A t t_{8}$ & 1 & 0.823 & 0.09 & $S n_{8}$ & 1 & 0.848 & 0.09 & - & - & - & - \\
\hline$A t t_{9}$ & 1 & 0.787 & 0.09 & $S n_{9}$ & 1 & 0.817 & 0.08 & - & - & - & - \\
\hline$A t t_{10}$ & 1 & 0.887 & 0.10 & $S n_{10}$ & 1 & 0.848 & 0.09 & - & - & - & - \\
\hline$A t t_{11}$ & 1 & 0.908 & 0.10 & $S n_{11}$ & 1 & 0.701 & 0.07 & - & - & - & - \\
\hline$A t t_{12}$ & 1 & 0.762 & 0.09 & $S n_{12}$ & 1 & 0.873 & 0.09 & - & - & - & - \\
\hline- & - & - & - & $S n_{13}$ & 1 & 0.788 & 0.08 & - & - & - & - \\
\hline
\end{tabular}




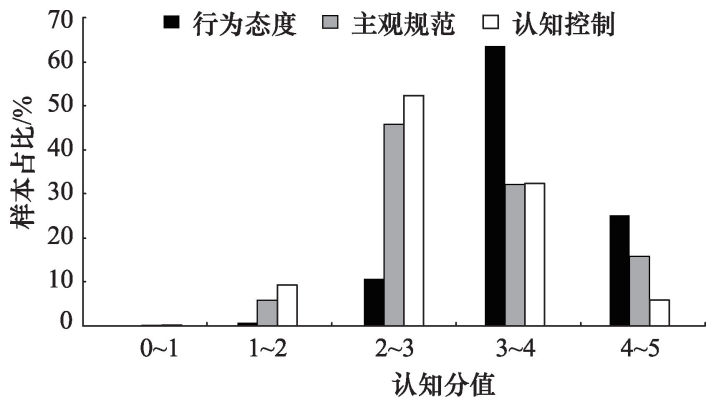

图 1 样本农户土地权属调整认知分值

Figure 1 Land ownership adjustment cognition scores of sample farmers

表 5 样本农户土地权属调整的行为分类

Table 5 Classification land ownership adjustment behavior of sample farmers

\begin{tabular}{lccc}
\hline \multicolumn{1}{c}{ 选项 } & 分值 & 频数 & 比重 $/ \%$ \\
\hline 没有参与权属调整 & 1 & 420 & 65.22 \\
消极地参与权属调整 & 2 & 8 & 1.24 \\
被动地参与权属调整 & 3 & 25 & 3.88 \\
较积极地参与权属调整 & 4 & 58 & 9.01 \\
非常积极地参与权属调整 & 5 & 133 & 20.65 \\
小计 & - & 644 & 100 \\
\hline
\end{tabular}

参与行为状况并不乐观。在已经参与权属调整的 224 户中,近 $60 \%$ 的农户抱有非常积极的参与态度， “消极”或“被动” 参与的农户约占样本比重的 5\%, 说明在已参与权属调整的农户之中, 积极的行为占 多数。

\section{2 农户认知与行为的一致性分析}

相关性分析是研究社会经济现象中不确定关 系的统计方法, $R^{2}$ 是相关性检验常用的方法 ${ }^{[30-32]}$ 。首 先用 $R^{2}$ 值直观地反映出农户关于农地整治权属调 整的认知和行为之间的相关性。再选取多值有序 的 Logistic 模型进行回归分析, 对比受访者及家庭 特征、耕地资源特征和村集体特征三个层面的解释 变量对农户认知和行为的偏效应差异。

\subsection{1 相关性检验}

相关性系数可反映变量之间的相关程度, 检验 结果表明在农地整治权属调整中, 农户认知与行为 表现出一定的相关性, 其中主观规范 $(\mathrm{SN})$ 与认知控 制 (PBC) 对农户行为 (Behavior) 表现出显著和低度 的相关性, 其 $R^{2}$ 值分别是 0.60 和 0.45 , 而行为态度 (ATT) 与农户行为 (Behavior) 的 $R^{2}$ 值是 0.19 , 对农户 行为 (Behavior)的解释能力十分微弱。
为了直观地展示农户认知和行为的相关度, 现 令 $X s_{i}\left(A T T_{i}\right.$, Behavior $\left._{i}\right) 、 Y s_{i}\left(S N_{i}\right.$, Behavior $\left._{i}\right) 、 Z s_{i}(P B-$ $\boldsymbol{C}_{i}$, Behavior $\left._{i}\right)$ 分别代表第 $i$ 个农户在农地整治权属 调整的认知(行为态度、主观规范、认知控制)分值和 行为分值的二维分布向量, 并将每个农户 (从 001 开 始编号)的三个维度认知分值和各自的行为分值进 行对应排列得到二维向量分布,结果如图 2 所示, 横 轴代表农户编号, 纵轴代表农户认知与行为的得分 值。从图 $2 \mathrm{a}$ 中的走向看, 行为态度 $(\mathrm{ATT})$ 与农户行 为 (Behavior) 明显没有一致性的趋势, 这与其相关 性系数仅为 0.19 的结果基本相对应; 图 $2 \mathrm{~b}$ 和图 $2 \mathrm{c}$ 则 显出主观规范 $(\mathrm{SN})$ 和认知控制 $(\mathrm{PBC})$ 的峰值和走向 与农户行为 (Behavior)的一致性相对明显。比较认 知控制 (PBC) 与主观规范 $(\mathrm{SN})$ 同行为的拟合性,从 局部数据的分布状况来看, 前者略差于后者(农户 编号 491 附近的数据), 由此可知二维图的分布结果 与 $R^{2}$ 值的大小排列较吻合。

\subsection{2 模型的计量与分析}

模型的因变量农户认知 $\left(Y_{\mathrm{r}}\right)$ 和行为 $\left(Y_{b}\right)$ 都是分 类变量,其中认知 $Y_{\mathrm{r}}$ 包括 $\mathrm{ATT} 、 \mathrm{SN}$ 和 $\mathrm{PBC}$ 三方面,按 照分值大小将认知水平分为 “很低” $\left(Y_{\mathrm{r}}=[0,1]\right)$ 、“较 低” $\left(Y_{\mathrm{r}}=(1,2]\right)$ 、“一般” $\left(Y_{\mathrm{r}}=(2,3]\right)$ 、“较高” $\left(Y_{\mathrm{r}}=(3,4]\right)$ 、 “很高” $\left(Y_{\mathrm{r}}=(4,5]\right)$ 五类; 而农户行为 $Y_{b}$ 则根据表 5 按 照分值 1 到 5 的顺序定义为 “没有参与” $\left(Y_{b}=1\right)$ 、“消 极参与” $\left(Y_{b}=2\right)$ 、“被动参与” $\left(Y_{b}=3\right)$ 、“较积极参与” $\left(Y_{b}=4\right)$ 、“非常积极参与” $\left(Y_{b}=5\right) 5$ 类。自变量包括受 访者及家庭特征(受访者年龄、户主受教育程度、家 庭农业收人比重)、耕地资源特征(耕地面积、耕地质 量、耕地破碎化程度)、村集体特征(村庄的经济水 平、距城镇的距离、社会经济组织)三个方面 ${ }^{[33,34]}$, 具 体的赋值规则见表6(见59页)。

借助 SAS 软件中因变量为多值有序的 Logistic 回归分析模块对农地整治权属调整中农户认知和 行为的影响因素开展计量分析,利用 SAS 中的编程 功能 input 所有的自变量和因变量, 在分类变量栏 “class”中输入 “Edu、Age、Fra、Qua、Eco、Dis、Ass”, 其他变量默认为连续变量。依次对认知的三个方 面和行为进行Logistic 回归, 并得到各自的结果。

首先进行模型的检验, 从表 7(见59页)中可以 看出行为态度 $(A T T)$ 、主观规范 $(S N)$ 、认知控制 

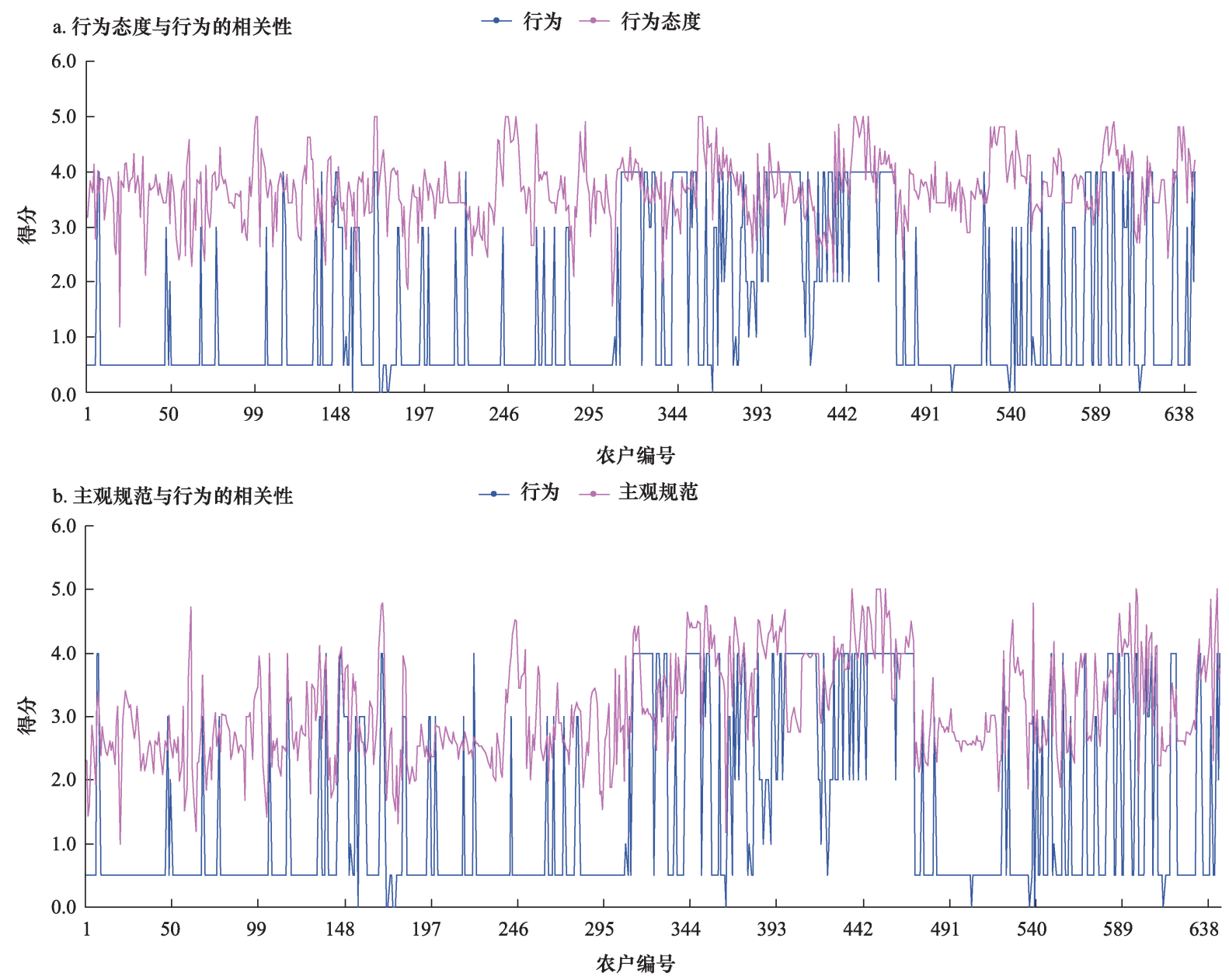

c. 认知控制与行为的相关性 $\quad \rightarrow$ 行为 - 认知控制



图 2 农户三个维度的认知与其行为的相关性

Figure 2 Relativity between cognition in three dimensions and behavior of farmers

(PBC) 和农户行为的 $\mathrm{P}$ 值均小于 0.0001 , 说明模型 有意义。平行线检验采取 SAS 中 “Proportional Odds Assumption”的得分检验, 从表 8 中可以看出农 户认知三个方面和行为的 $P$ 值均大于 0.05 , 所以模 型通过平行线检验, 即解释变量在各等级中的效应
保持一致,因此可采用有序的Logistics 模型进行回 归分析。

(1) 回归的结果如表 9 所示。在农户及家庭特 征变量中, “受访者年龄”在 5\%的水平上通过了对 行为态度 (ATT) 的负向检验, 且对主观规范 $(\mathrm{SN})$ 和 


\section{表 6 影响农户认知和行为的解释变量}

Table 6 Explanatory variables of farmers' cognition and behavior

\begin{tabular}{|c|c|c|}
\hline 类别 & 变量 & 赋值规则 \\
\hline \multirow[t]{3}{*}{ 受访者及家庭特征 } & 受访者的年龄 $(A g e)$ & $1=40$ 岁及以下; $2=41 \sim 55$ 岁; $3=56 \sim 65$ 岁; $4=65$ 岁以上 \\
\hline & 户主受教育程度( Edu) & $1=$ 小学及以下 $; 2=$ 初中 $; 3=$ 高中或中专 $; 4=大$ 专及以上 \\
\hline & 家庭农业收人比重 $($ Aip ) & 农业收人占家庭总收人的比例 \\
\hline \multirow[t]{3}{*}{ 耕地资源特征 } & 耕地面积 $(A c r)$ & 家庭承包耕地的总面积 \\
\hline & 耕地质量 $(Q u a)$ & 1=很差; $2=$ 较差; $3=$ 一般; 4=较好;5=很好 \\
\hline & 耕地破碎化程度 (Fra) & 1=很低;2=较低;3=一般;4=较高; $5=$ 很高 \\
\hline \multirow[t]{3}{*}{ 村集体特征 } & 村经济发展水平 $(E c o)$ & 1=很低;2=较低;3=一般;4=较高; 5=很高 \\
\hline & 距城镇距离 (Dis) & $1=$ 很远 ; $2=$ 较远 $; 3=$ 一般; $4=$ 较近 $; 5=$ 很近 \\
\hline & 成立社会经济组织 $(A s s)$ & $1=$ 是 $; 2=$ 否 \\
\hline
\end{tabular}

表 7 模型显著性检验

Table 7 Model significance test

\begin{tabular}{|c|c|c|c|c|}
\hline \multicolumn{2}{|c|}{ 指标 } & ATT & SN & $\mathrm{PBC}$ \\
\hline \multicolumn{2}{|c|}{$\operatorname{Pr}>$ ChiSq } & $<0.0001$ & $<0.0001$ & $<0.0001$ \\
\hline \multicolumn{5}{|c|}{ 表 8 平行线检验 } \\
\hline & & \multicolumn{3}{|c|}{ Table 8 Parallel line test } \\
\hline & & 卡方 & DF & P值 \\
\hline \multirow{3}{*}{ 认知 } & ATT & 99.400 & 84 & 0.119 \\
\hline & SN & 93.051 & 84 & 0.234 \\
\hline & PBC & 133.855 & 112 & 0.078 \\
\hline 行为 & Behavior & 91.303 & 75 & 0.097 \\
\hline
\end{tabular}

农户行为 (Behavior)都通过了 $1 \%$ 水平的正向检验， 说明年龄偏大的农户对农地整治权属调整的认知 不如年轻人, 而年龄越大的农户所感受到的来源于
邻里和村集体开展权属调整的压力越大, 行为也越 积极。由于年轻人对信息的理解和接受能力更强, 所以其认知更深人,而留在村集体务农的农户年龄 较大, 其活动范围相对固定, 易形成稳定的社会网 络,能感知来源于周围环境的压力,故在“伙伴团体 效应”的作用下,行为更易表现出积极性。“家庭农 业收人比重” 在 $5 \%$ 的水平上通过了对主观规范 ( SN)的正向检验,表明农户对农业活动的依赖性会 影响其对权属调整参与压力感知的深刻性, 而其对 行为的负向显著性,说明以农业收人为主的农户行 为相对消极, 可能是此类农户在农地整治权属调整 中协调的困难较突出, 导致了其行为的消极性。

(2)从耕地资源特征看, “承包耕地的面积”是耕 地特征变量中唯一通过显著性检验的变量, 在 $1 \%$

表 9 影响因素的显著性检验结果

Table 9 The significance test result of influencing factor

\begin{tabular}{|c|c|c|c|c|c|c|c|c|c|}
\hline & \multirow[b]{3}{*}{ 自变量 } & \multicolumn{8}{|c|}{ 因变量 } \\
\hline & & \multicolumn{2}{|c|}{ 认知 ATT } & \multicolumn{2}{|c|}{ 认知 SN } & \multicolumn{2}{|c|}{ 认知 $\mathrm{PBC}$} & \multicolumn{2}{|c|}{ 行为 Behavior } \\
\hline & & Estimate & $\mathrm{p}$ & Estimate & $\mathrm{p}$ & Estimate & $\mathrm{p}$ & Estimate & $\mathrm{p}$ \\
\hline \multirow{3}{*}{$\begin{array}{l}\text { 受访者及 } \\
\text { 家庭特征 }\end{array}$} & 受访者年龄 & $-0.281 * *$ & 0.017 & $0.324 * * *$ & 0.007 & -0.074 & 0.522 & $1.406^{* * *}$ & 0 \\
\hline & 户主受教育程度 & -0.280 & 0.090 & 0.267 & 0.193 & -0.114 & 0.620 & -0.011 & 0.070 \\
\hline & 家庭农业收人比重 & 0.019 & 0.090 & $0.027 * *$ & 0.049 & 0.012 & 0.291 & $-0.037 * * *$ & 0.002 \\
\hline \multirow{3}{*}{$\begin{array}{l}\text { 耕地资源 } \\
\text { 特征 }\end{array}$} & 承包耕地的面积 & -0.020 & 0.128 & 0.006 & 0.662 & $-0.036^{* * *}$ & 0.006 & $0.227 * * *$ & 0 \\
\hline & 承包耕地的质量 & 0.139 & 0.400 & -0.372 & 0.066 & -0.236 & 0.159 & 0.033 & 0.097 \\
\hline & 农地破碎化程度 & -0.010 & 0.134 & 0.176 & 0.077 & -0.003 & 0.693 & 0.520 & 0.130 \\
\hline \multirow{3}{*}{$\begin{array}{l}\text { 村集体 } \\
\text { 特征 }\end{array}$} & 村经济发展水平 & $-0.104 * * *$ & 0 & $1.563 * * *$ & 0 & $1.181 * * *$ & 0.001 & -4.020 & 0.970 \\
\hline & 距城镇的距离 & $1.115^{* *}$ & 0.013 & $-1.107 * * *$ & 0.004 & $-1.129 * * *$ & 0.001 & 0.435 & 0.160 \\
\hline & 成立社会经济组织 & 0.793 & 0.134 & $-0.636^{* * *}$ & 0.003 & $0.807 * * *$ & 0 & $-0.244 * * *$ & 0.010 \\
\hline
\end{tabular}

注: Estimate 为回归系数; $\mathrm{P}$ 为显著性概率; $* * * 、 * *$ 分别代表在 $1 \% 、 5 \%$ 水平上显著。 
的水平上分别通过了对认知控制 ( $\mathrm{PBC}$ )的负向检验 和行为 (Behavior)的正向检验, 表明承包耕地面积 越大的农户对农地整治权属调整的结果预估越悲 观, 但是其行为却越积极, 总结原因可能是承包耕 地面积较大的农户往往也拥有较多的地块, 从而加 深其对协调困难性的主观感受, 但是地块多、面积 大的农户一旦参与土地权属调整, 涉及的范围也更 大, 其行为从客观上就表现得更积极。

(3)村集体特征变量对农户认知的影响相对于 行为而言更显著, 其中 “村经济发展水平” 和“距城 镇的距离”两个因子只对认知通过显著性检验, 对 行为的影响则不显著。“村经济发展水平”对主观规 范 $(\mathrm{SN})$ 和认知控制 (PBC) 都具有正向显著性影响, 即经济相对发达的地区农户感受到外部开展农地 权属调整的压力更大, 对结果预判更乐观; 经济较 发达地区往往社会网络更复杂, 所以“伙伴团体效 应”更显著, 农户对自身禀赋和动用资源能力的预 估也更加乐观, 而其对行为态度 (ATT)的负向显著 性则说明在经济水平较高的农村地区, 农户对农地 权属调整的积极作用认知反而不敏感, 可能是因经 济水平较发达地区农户的兼业化程度相对高, 其对 农业活动影响的感知相对较弱。“距城镇的距离”通 过了对认知控制 $(\mathrm{PBC})$ 和主观规范 (SN)的负向检验 和行为态度 (ATT)的正向检验, 说明距城镇越近, 人 们对农地整治权属调整的积极作用越不认可, 开展 权属调整的外部压力却越小, 且对结果预估越差。 距离城镇越近的农户间联系相对松散, 感知到的来 源于村集体和邻里的压力较小,其被征地的可能性 更大, 土地利用关系更复杂, 协调更困难, 因此农户 对农地整治权属调整的结果预判更加悲观。“是否 成立社会经济组织” 是这组因素中唯一对农户的认 知和行为都具有显著性影响的变量, 对主观规范 $(\mathrm{SN})$ 和行为的负向显著性则表明在成立经济组织 的村集体,农户之间联系更紧密,农户之间的组织 性提升了其行为的积极性。对认知控制 (PBC)的正 向显著性说明组织的存在弱化了农户对于自身能 力和禀赋的评价, 同时由于在成立经济组织的地 区, 土地利用关系趋于复杂的可能性使得农户对土 地权属调整的结果预估更易悲观。

综上所述, 三个方面的解释变量对农户认知及
行为影响的显著性和方向有一定的差异。其中,行 为 (Behavior)与主观规范 $(\mathrm{SN})$ 有两个显著性和方向 均一致的解释变量 ( “年龄” 和 “是否成立社会经济 组织”), 行为态度 (ATT) 和认知控制 (PBC) 各有一 个显著性影响因素与行为 (Behavior)重合, 但是方 向相异。即在认知的三个方面中, 只有主观规范 $(\mathrm{SN})$ 与行为 (Behavior)的一致性相对较高, 而行为 态度 (ATT) 和认知控制 (PBC) 与行为的相关性较弱, 这一结果和前文相关性检验的结果较吻合。在相 关性检验中, 行为 (Behavior)与主观规范 (SN) 相关 度最高, 而与行为态度 (ATT) 不具有相关性。由此 可知, 农户认知和行为之间存在相关性, 但不具备 完全的一致性, 且这种相关性在农户认知机制内部 表现出不均衡性。

\section{5 结论与建议}

\section{1 研究结论}

（1)农户对农地整治权属调整的认知状况在认 知机制内部表现出不均衡性。农户的行为态度认 知状况最好, 主观规范和认识控制的认知状况接 近, 都明显低于行为态度, 农户的行为缺乏积极性。

(2)在农地整治权属调整中,农户认知与行为不 具备完全的一致性。相关性检验和 Logistic 回归的 结果都表明在农户的认知机制的三个方面中, 主观 规范与农户行为的一致性最高, 而行为态度和认知 控制虽然从 $R^{2}$ 值上反映出与农户行为有一定的相关 性,但回归的结果表明它们与行为不具备一致性。

(3)从农户认知和行为的影响因素层面来看, “受访者年龄”、“家庭农业收人比重”、“承包耕地的 面积”、“是否成立社会经济组织”对行为态度、主观 规范和认知控制和农户的行为都产生了影响,但作 用方向有差异。

\section{2 政策建议}

（1)做好农地整治权属调整的信息公开和意见 征询工作。农户是农地权属调整的主体, 制度环境 影响农户认知中的主观规范, 而主观规范与农户行 为较高的一致性则要求村委会及时将权属调整工 作的信息向农户公开。信息公开便于农户了解工 作的进展, 意见征询有利于让农民参与权属调整方 案的制定, 这不仅能提升村民的主观规范和认知控 
制的状况，更能让村民感受到政策和制度环境给予 个体的无形压力, 从而促进农地整治中土地权属调 整工作的开展。

(2)重视农地整治权属调整的宣传动员工作。 针对农户的行为易受到邻里和村集体影响的特征, 结合农村社会网络关系紧密的现状,村委会要成立 权属调整工作小组, 有重点、有方向地向农户宣传 土地权属调整的意义及相关工作。利用农民行为 的 “伙伴团体效应”, 营造人人参与的氛围, 并及时 与村民沟通,为农户创造良好的参与环境。

(3)发挥农村社会经济组织的作用。农村社会 经济组织加深了农户间本就密切的联系, 也无形中 增强了农户在农事活动中的组织性和归属感。因 此在农户参与农地整治权属调整过程中, 村集体要 充分发挥诸如农业合作社和耕地保护协会等农村 社会经济组织的带动作用, 通过增强农户所感受到 的外部环境的压力来提升其行为的积极性。同时, 利用组织将农户分散的利益需求集中化,降低在农 地整治中实施土地权属调整的利益协调难度, 从而 减少政策推行的阻力。

\section{3 讨论}

论文在探讨解释变量对于农户认知和行为的 偏效应差异时,选取了受访者个体及家庭、耕地资 源和村集体三方面的特征作为影响因子,但是在实 际中, 村集体是否开展农地整治权属调整工作则直 接影响着农户的参与行为及其积极性,也可能影响 其他解释变量对于农户行为的作用。本研究中为 了能比较出解释变量对于农户认知和行为的作用 差异,同时出于稳定性和独立性的考虑, 将可以同 时影响农户认知和行为解释变量作为影响因子,而 没有纳人村集体行为这一变量。这也是今后研究 的一个展望点, 可考虑将村集体的行为作为组织支 持纳人计划行为理论体系中, 进一步研究农户认知 和行为的内在作用机理。

\section{参考文献(References):}

[1] 关江华. 土地整理权属调整研究[D]. 武汉: 华中农业大学, 2008. [Guan J H. Study on Adjustment of Land Consolidation Ownership[D]. Wuhan: Huazhong Agricultural University, 2008. ]

[2] 陈晓军. 国内外农村土地整治权属调整研究进展 [J]. 国土科技
管理, 2012, 29(5): 25-26. [Chen X J. Research progress of ownership adjustment of rural land regulation in domestic and foreign[J]. Scientific and Technological Management of Land and Resources, 2012, 29(5): 25-26. ]

[3] 邓正华, 张俊彪, 许志祥, 等. 农村生活环境整治中农户认知与 行为响应研究-以洞庭湖湿地保护区水稻主产区为例[J. 农业 技术经济, 2013, (2): 72-78. [Deng Z H, Zhang J B, Xu Z X, et al. Study on Farmers' cognition and behavior response in rural environment improvement project-taking the main rice producing areas in Dongting Lake wetland reserve as an example[J]. Journal of Agrotechnical Economics, 2013, (2): 72-78. ]

[4] 张董敏, 齐振宏, 李欣芯, 等. 农户两型农业认知对行为响应的 作用机制-基于 TPB 和多群组 SEM 的实证研究 [J]. 资源科学, 2015, 37(7): 1482-1484. [Zhang D M, Qi Z H, Li X R, et al. The mechanism of farmers' two type agricultural cognition behavior responses-empirical research based on TPB and multi-group SEM [J]. Resources Science, 2015, 37(7): 1482-1484. ]

[5] 宋言奇. 发达地区农民环境意识调查分析-以苏州市 714 个样 本为例[J]. 中国农村经济, 2010, (1): 53-62. [Song Y Q. Investigation and analysis of farmers' environmental awareness in developed areas-taking 714 samples from Suzhou city as an example [J]. Chinese Rural Economy, 2010, (1): 53-62. ]

[6] 王常伟, 顾海英. 农户环境认知、行为决策及其一致性检验-基 于江苏农户调查的实证分析[J]. 长江流域资源与环境, 2012, 21(10): 1205-1207. [Wang C W, Gu H Y. Farmer's environmental cognition, behavior decision and their consistency test-an empirical analysis based on the survey of farmers in Jiangsu [J]. Resources and Environment in the Yangtze Basin, 2012, 21(10): 1205-1207. ]

[7] 陈江婴. 农村环境连片整治工程中公众参与行为的影响机理研 究[D]. 福州: 福建农林大学, 2013. [Chen J Y. Study on the Mechanism of Public Participation in Rural Environmental Improvement Project[D]. Fuzhou: Fujian Agriculture and Forestry University, 2013. ]

[8] 刘燕, 杨庆媛, 何春燕, 等. 农户对土地整治项目管理的认知与 响应研究-基于重庆市 6 个区县 22 个村的调查[J]. 西南师范大 学学报(自然科学版), 2015, (7): 143-150. [Liu Y, Yang Q Y, He C Y, et al. Farmers' cognition and response to land consolidation project management-based on the investigation of 22 villages in 6 districts and counties of Chongqing City[J]. Journal of Southwest China Normal University(Natural Edition), 2015, (7): 143-150. ]

[9] 赵微, 周惠, 杨钢桥, 等. 农户参与农地整理项目建后管护的意 愿与行为转化研究: 以河南邓州的调查为例 $[\mathrm{J}]$. 中国土地科 学, 2016, 30(3): 56-57. [Zhao W, Zhou H, Yang G Q, et al. Research on the willingness and behavior transformation of farmers' participation after constmction of land consolidation project: take the survey in Henan, Dengzhou as an example[J]. Chinese Land Science, 2016, 30(3): 56-57. ] 
[10] 汪萍, 汪文雄, 杨海霞, 等. 农民有效参与对农地整治项目绩效 的影响效应研究-基于项目管理行为的中介效应分析[J]. 资源 科学, 2016, 38(3): 395-406. [Wang P, Wang W X, Yang H X, et $a l$. The effect of farmers' effective participation on the performance of rural land consolidation project-mediating effect analysis based on project management behavior[J]. Resources Science, 2016, 38(3): 395-406. ]

[11] 汪文雄, 钱圣, 杨钢桥. PPP 模式下农地整理项目前期阶段效率 影响机理研究[J]. 资源科学, 2013, 35(2): 341-352. [Wang W X, Qian S, Yang G Q. Study on the efficiency influencing mechanism of land consolidation project during the early stage of PPP model [J]. Resources Science, 2013, 35(2): 341-352. ]

[12] 王文玲, 阚西浔, 汪文雄, 等. 公众参与土地整理的研究综述 [J]. 华中农业大学学报(社会科学版), 2011, (3): 71-75. [Wen W L, Kan Y X, Wang W X, et al. Review of public participation in land consolidation [J]. Journal of Huazhong Agricultural University Social Sciences Edition, 2011, (3): 71-75. ]

[13] 石峡. 土地整治公众参与机制研究[D]. 北京: 中国农业大学, 2015. [Shi X. Study on the Mechanism of Public Participation in Land Consolidation[D]. Beijing: China Agricultural University, 2015. ]

[14] 李宴. 土地整理公众参与权及其法律实现[J]. 农村经济, 2015, (7): 35-39. [Li Y. Public participation right of land consolidation and its legal realization[J]. Rural Economy, 2015, (7): 35-39. ]

[15] 王瑗玲, 李占军, 张建国, 等. 农民参与土地整理现状及政策建 议[J]. 中国土地科学, 2008, 22(5): 47-50. [Wang A L, Li Z J, Zhang J G, et al. The present situation and policy suggestions of farmers participation in land consolidation [J]. Chinese Land Science, 2008, 22(5): 47-50. ]

[16] 汪文雄, 李敏, 余利红, 等. 农地整治项目农民有效参与的实证 研究[J]. 中国人口·资源与环境, 2015, 25(7): 128-137. [Wang W X, Li M, Yu L H, et al. Empirical study on farmers' effective participation in land consolidation projects[J]. China Population Resources and Environment, 2015, 25(7): 128-137. ]

[17] 汪文雄, 汗萍, 罗冰, 等. 农户有效参与提升农地整治项目绩效 的机理研究[J]. 中国人口·资源与环境, 2016, 26(7): 159-168. [Wang W X, Wang P, Luo B, et al. Study on the mechanism of farmers' effective participation and farmland remediation project performance improvement[J]. China Population Resources and Environment, 2016, 26(7): 159-168. ]

[18] 余振国, 吴茨芳. 我国土地整理权属调整的机制建设研究[J]. 南 京农业大学学报(社会科学版), 2003, 26(2): 118-120. [Yu Z G, Wu C F. Study on the mechanism construction of ownership adjustment in land consolidation in China[J]. Journal of Nanjing Agricultural University(Social Sciences Edition), 2003, 26(2): 118-120. ]

[19] 胡昱东, 吴次芳. 我国农村土地整理中土地权属调整问题研究 [J]. 西北农林科技大学学报 (社会科学版), 2009, 9(1): 7-9. [Hu Y D, Wu C F. Study on the adjustment of land rights in rural land consolidation in China[J]. Journal of Northwest A\&F University(So- cial Science Edition), 2009, 9(1): 7-9. ]

[20] 关江华, 张术. 基于主成分的土地整理权属调整影响因素研 究-以湖北省沙洋县为例 [J]. 国土资源科技管理, 2010, 27(5): 90-92. [Guan J H, Zhang S. Study on the influencing factors of ownership adjustment land consolidation based on principal component analysis-taking Shayang County of Hubei Province as an example[J]. Scientific Technological Management of Land and Resources, 2010, 27(5): 90-92. ]

[21] 韩立达, 王艳西. 城乡建设用地增减挂钩中土地权属调整研究 [J]. 中国土地科学, 2016, 30(4): 21-27. [Han L D, Wang Y X. Study on the adjustment of land rights in the link between urban and rural construction land increase and decrease[J]. Chinese Land Science, 2016, 30(4): 21-27. ]

[22] 王沿军. 如何制定土地开发整理项目中的土地权属调整方案 [J]. 资源・产业, 2005, 7(2): 44-45. [Wang Y J. How to formulate land ownership adjustment program in land development and consolidation projects?[J]. Resources \& Industries, 2005, 7(2): 44-45. ]

[23] 段文婷, 江光荣. 计划行为理论评述[J]. 心理科学进展, 2008, 16 (2): 315-320. [Duan W T, Jiang G R. A review of Theory of Planned Behavior[J]. Advances in Psychological Science, 2008, 16(2): 315320.]

[24] Ajzen I. The Theory of Planned Behavior[J]. Organizational Behavior and Human Decision Processes, 1991, 50(2): 179-211.

[25] 赵建欣, 张忠根. 基于计划行为理论的农户安全农产品供给机 理探析[J]. 财贸研究, 2007, 18(6): 40-45. [Zhao J X, Zhang Z G. An analysis of farmers' agricultural products supply mechanism based on Theory of Planned Behavior [J]. Finance and Trade Research, 2007, 18(6): 40-45. ]

[26] 王建华, 马玉婷, 㫤熳璐. 农户农药残留认知及其行为意愿影响 因素研究-基于全国五省 986 个农户的调查数据[J]. 软科学, 2014, 28(9): 134-138. [Wang J H, Ma Y T, Chao M L. Study on farmers' cognition of pesticide residues and the factors affecting their behavioral-based on the survey data of 986 farmers in five provinces of China[J]. Soft Science, 2014, 28(9): 134-138. ]

[27] 侯博, 应瑞瑶. 分散农户低碳生产行为决策研究-基于 TPB 和 SEM 的实证分析[J]. 农业技术经济, 2015, (2): 4-13. [Hou B, Ying R Y. Decision making of low carbon production behavior of decentralized farmers: an empirical analysis based on TPB and SEM [J]. Journal of Agrotechnical Economics, 2015, (2): 4-13. ]

[28] 房凯. 不同生计类型农户土地流转研究[D]. 重庆: 西南大学, 2010. [Fang K. Study on Land Transfer of Farmers with Different Livelihood Types [D]. Chongqing: Southwest University, 2010. ]

[29] 陈晓红, 汪朝霞. 苏州农户兼业行为的因素分析[J]. 中国农村经 济, 2007, (4): 25-31. [Chen X H, Wang C X. Factor analysis of rural household Part-time behavior in Suzhou[J]. Chinese Rural Economy, 2007, (4): 25-31. ]

[30] 张婷, 吴燕燕, 李来好, 等. 咸鱼品质的质构与感官相关性分析 [J]. 水产学报, 2013, 37(2): 305-306. [Zhang T, Wu Y Y, Li L H, 
et al. Texture and sensory correlation analysis of salted fish quality

[J]. Journal of Fisheries of China, 2013, 37(2): 305-306. ]

[31] 杨存建, 刘纪远, 黄河, 等. 热带森林植被生物量与遥感地学数 据之间的相关性分析 [J]. 地理研究, 2005, 24(3): 476-478 [Yang C J, Liu J Y, Huang H, et al. Correlation analysis between biomass of tropical forest vegetation and remote sensing geological data[J]. Geographical Research, 2005, 24(3): 476-478. ]

[32] 散釷龙, 刘旋峰, 牛长河, 等. 杏果实成熟度特性参数与果柄分 离力的相关性分析[J]. 农业工程学报, 2013, 29(23): 64-65. [San J L, Liu X F, Niu C H, et al. Correlation analysis between fruit maturity parameters and fruit stalk separation ability in apri$\cot [\mathrm{J}]$. Transactions of the Chinese Society of Agricultural Engineer- ing, 2013, 29(23): 64-65. ]

[33] 田甜, 杨钢桥, 汪文雄, 等. 农地整治项目农民参与行为机理研 究-基于嵌人性社会结构理论[J]. 农业技术经济, 2015, (7): 1626. [Tian T, Yang G Q, Wang W X, et al. Study on the mechanism of farmers' participation in land consolidation project-based on the Theory of Embedded Social Structure [J]. Journal of Agrotechnical Economics, 2015, (7): 16-26. ]

[34] 汪文雄, 王文玲, 朱欣, 等. 农地整理项目实施阶段农户参与程 度的影响因素研究[J]. 中国土地科学, 2013, (7): 62-68. [Wang W X, Wang W L, Zhu X, et al. Study on the influencing factors of farmers' participation degree in the implementation stage of land consolidation project[J]. Chinese Land Science, 2013, (7): 62-68. ]

\title{
Consistency of farmers' cognition and behavior in the adjustment of land ownership under farmland consolidation
}

\author{
WANG Mei, WANG Wenxiong \\ (School of Public Administration, Huazhong Agricultural University, Wuhan 430070, China)
}

\begin{abstract}
The consistency relationship between the cognition and behavior of farmers to the adjustment of land ownership is not only an important part of the theory of farmland ownership adjustment, but also an important reference for policy formulation for land ownership. In order to explore consistency of farmer cognition and behavior in the adjustment of farmland regulation, we examined consistency using correlation analysis, and analyzed difference in the partial effect of the influence of factors about individual and family characteristics, cultivated land resources and village characteristics to farmer cognition and behavior under the Theory of Planned Behavior. We used questionnaire data from 644 households in seven cities (counties) in Hubei. Results show that the cognitive status of farmers was unbalanced within the cognitive mechanism, and that behavioral motivation was lacking. From the perspective of consistency, correlation analysis and modeling showed that consistency Between Subjective Norms and behavior was high, while Attitude Toward The behavior and Perceived behavior Control basically had no consistency with behavior. On the basis of the results of this study, we propose strengthening information publicity and consultation, paying attention to propaganda and mobilization, and giving full play to the role of rural social and economic organizations to promote the smooth implementation of farmland ownership adjustment.
\end{abstract}

Key words: land ownership adjustment; farmers' cognition and behavior; theory of planned behavior; correlation test; Logistic Regression 